To cite this article:

Thistlethwaite J, Khalili H, Grymonpre R, Atack L, Gilbert J, Espin S, Donelly C, Iglarsh A, Green C, Riva $J$ and Namavarian A (2013) Introducing the Global Research Interprofessional Network (GRIN).

Journal of Interprofessional Care; 27, 2: 107-109. DOI: 10.3109/13561820.2012.718814

To link to this article: http://dx.doi.org/10.3109/13561820.2012.718814

\title{
INTRODUCING THE GLOBAL RESEARCH INTERPROFESSIONAL NETWORK (GRIN)
}

\section{INTRODUCTION}

A group of friends and colleagues with a common passion for interprofessional education for collaborative patient-centred practice (IECPCP)² met in Toronto, Canada in May 2012.

Participants were identified for this orientation meeting to ensure representation by educators, clinicians, graduate students and international collaborators. Our aim was to discuss how the research agenda for IECPCP might be advanced with an emphasis on the nurturing and development of new researchers in the field. Discussion led to adoption of the name Global Research Interprofessional Network (GRIN), and agreement on the vision, mission and values for this new network (Box 1).

In this editorial we discuss the context and rationale behind this new global initiative, and present our thoughts on how people may become involved in our further activities.

\section{Context and rationale:}

This project is initially being funded through a CIHR (Canadian Institutes for Health Research: the major federal agency responsible for funding health research in Canada) meeting and planning grant in conjunction with a core group of members of CIHC (the Canadian Interprofessional Health Collaborative - see www.cihc.ca) under the leadership of Ruby Grymonpre (University of Manitoba) and Hossein Khalili (Fanshawe College). As 
interprofessional enthusiasts are aware, Canada is a world leader in the development of IECPCP and its, delivery and evaluation. For a four year period beginning in2004, Health Canada invested over $\$ 20$ million through its call for proposals to support the development and implementation of interprofessional education for collaborative patient centred practice, resulting in 21 projects, many of which have been reported in this journal.

To increase collaboration between researchers and knowledge users and to facilitate discussion of the common challenges, interests and research findings of IECPCP, John Gilbert (University of British Columbia) established CIHC with funding from Health Canada. The CIHC aims to work at the interface of health, education and the professions to foster uptake of promising practices that will promote interprofessional education and collaborative practice and enhance personcentred health and wellness. Several members of the CIHC were involved with the WHO Study Group on IECPCP (of which John Gilbert was Co-Chair with Jean Yan of the WHO) that subsequently published the 'Framework for Action on Interprofessional Education and Collaborative Practice' (World Health Organization, 2010).

Drawing on the 'Research Capacity Building in Health Care Framework' developed by Cooke (2005), the research and evaluation subcommittee of the CIHC undertook a mapping exercise to identify how best to build research capacity in IECPCP (Suter et al, 2011). Cooke (2005) described six principles of capacity building: 1 . skills and confidence; 2 . ensuring the research is 'close to practice'; 3. developing linkages and partnerships; 4. developing appropriate dissemination; 5. investments in infrastructure; and 6. building elements of sustainability and continuity. Through the mapping exercise, the committee identified three of the six Cooke principles as highest priority: principles 2,3 and 4 . The CIHC-ResearchNet (www.cihc.ca/researchnet) was established on December 2009 (under the leadership of Hossein Khalili) as a direct response to two of these three priorities: principles 3 and 4. CIHCResearchNet's vision is: 'A national interprofessional health research network of health 
program students, faculty/educators, researchers, clinicians/practitioners, administrators, and organizational leaders engaged in collaborative research and knowledge translation to advance interprofessional education and collaborative person-centred practice (CIHC, 2009).

To date the efforts of the CIHC-ResearchNet have been largely targeted at stakeholders at the national level, hence the stimulus to seek funding from the CIHR to expand its scope to become a global network. Networks can function as communities of practice (Wenger, 1998). There is considerable but highly variable evidence that rich, intense communication with other individuals and groups can stimulate creativity and research productivity (e.g. Adams, Black, Clemmons \& Stephan, 2005; Lee \& Bozeman, 2005; Heinze, Shapira, Rogers \& Senker, 2009). The volume of literature on the effects of international research collaboration on research performance is steadily increasing (e.g. Ordóñez-Matamoros \& Cozzens, 2010). Research collaboration is largely viewed as an important enabler; it supports the exchange of ideas, experience and information. Global collaboration, by increasing research unit size and involving multiple sites, can strengthen the generalizability of research results and support international visibility (Horta \& Lacy, 2011). It also has the potential to situate practices by providing comparative evidence that support initiatives in diverse socio-cultural contexts. Although some researchers report that collaboration can lead to the inefficient use of resources, and crowding out effects (Cummings \& Kiesler, 2005), others describe the incredible complexity of global collaborations including communication, culture, commitment, and challenges as part of the reality of getting work done (Masiello, 2009).

\section{Global Research Interprofessional Network: goals and planned activities}

The CIHC-ResearchNet met for over two years via telephone and Skype to formulate plans and secure funding. Members of the group were able to collaborate in presentations at several international meetings. However, it was difficult to create a comprehensive strategic plan to guide the expansion of the project using only these forms of communication. Under the 
auspices of the CIHR team meeting grant the workshop in Toronto on May 11-12, 2012 brought together 15 educators, researchers, graduate students and clinicians from Canada, the USA, the UK and Australia. Prior to this meeting, proposed future goals for this new network included the need to:

- Build international capacity for, and to facilitate research in IECPCP

- Stimulate research interests in IECPCP by a growing number of graduate students - the network views graduate education, and particularly the building of doctoral programs in IECPCP, as key elements of sustainability for our emerging field

- Foster new, and enhance existing, global interprofessional collaborations among and between graduate students, faculty/educators, practitioners, organizations and other knowledge users who are interested in conducting, funding or uptake of research in IECPCP

- Provide a virtual forum/platform for global knowledge generation and translation (synthesis, dissemination, exchange and application) relevant to IPECP

- Advance innovation in IECPCP by providing a global vehicle for translating the researchbased evidence for best-practice interprofessional education and practice.

The workshop opened with presentations relevant to IECPCP research and networking experiences in the UK, USA, and Australia. Sustainability was a common challenge identified by all participants. Participants acknowledged that most already belong to numerous networks and associations. Therefore, it is imperative that the GRIN be innovative and offers something unique.

As part of the meeting preparation, we had performed a literature synthesis, with the assistance of two baccalaureate students, to identify best practices in international research models. We also searched the Internet for well-designed collaborative research websites that demonstrated excellence in enhancing communication and resource sharing. This exercise indicated that the 
key factors for a sustainable interprofessional collaboration would need to include the maintenance of dialogue, ensuring clarity, respecting diversity, and engagement in process/contextual factors.

The working group agreed that in further thinking about GRIN's purpose it would be important to identify possible stakeholder groups, participants and advocates. GRIN will need to be inclusive of target groups (service users/consumers/patients/clients, students, policy makers, health and education administrators). Moreover GRIN will endeavour to promote an interdisciplinary approach that means being inclusive of disciplines beyond the traditional health professions such as linguistics, sociology, anthropology, economics, political sciences and others. GRIN recognizes that its work will be strengthened by number diversity and quality. Since IECPCP networks already exist, the emerging GRIN will need to ensure that it is complementary rather than competitive or duplicative. However, we believe that GRIN is unique with having research in IECPCP as its primary focus, although other existing organizations all serve as advocates for research in this area.

Relevance, buy-in and both bonding and bridging social capital (Field, 2003) for members were key principles explored in the meeting, and were seen as imperative for ensuring a sustainable network. The working group debated other factors that might make GRIN more relevant including open access to a website, synchronous or real time access, and posting available to all. The working group indicated the need to develop a research 'space' with a global focus that will showcase regional IECPCP. Future research programs should involve global partnerships and include both high-quality quantitative and qualitative methodologies in keeping with previous systematic review recommendations in this area. There was strong support in the group for the need to bridge the gap between theory and research, while at the same time establishing solid researcher mentor/mentee and more formal supervision relationships as core functions. 


\section{GRIN Next Steps}

We are in the process of developing an international environmental scan and needs assessment to survey a range of stakeholders including interprofessional networks in order to identify priority research areas and potential sources of funding . The survey will explore respondents' needs and wants with respect to resources, support and training, as well as their thoughts on the aims of the network and its proposed activities. GRIN plans to have an online presence potentially via a range of social media. The working group hopes that readers of this journal and interprofessional advocates, will become involved in GRIN. The working group welcomes feedback as we move forward with this project.

\section{Note}

1. Note that we are using IECPCP (interprofessional education for collaborative patient-centred practice) in this editorial rather than IPECP (interprofessional education for collaborative practice)

\section{REFERENCES}

Adams, J. D., Black, G. C., Clemmons, J. R., \& Stephan, P. (2005). Scientific teams and institutional collaborations: Evidence from US universities, 1981-1999. Research Policy, 34(3), 259-285.

CIHC (2009). CIHC-ResearchNet. Available at: http://www.cihc.ca/regional/cihcresearchnet

Cooke, J. (2005). A framework to evaluate research capacity building in health care. BMC Family Practice 2005, 6:44 doi:10.1186/1471-2296-6-44.

Cummings, J. N., \& Kiesler, S. (2005). Collaborative research across disciplinary and organizational boundaries. Social Studies of Science, 35(5), 703-722.

Field, J. (2003). Social Capital. London: Routledge.

Heinze, T, Shapira, P, Rogers J, D. \& Senker J,M. (2009. Organizational and institutional influences on creativity in scientific research. Research Policy, 38, 610-623.

Horta, H. \& Austin Lacy, T. (2011). How does size matter for science? Exploring the effects of research unit size on academics' scientific productivity and information exchange behaviors Science and Public Policy, 38(6), 449-460. 
Lee, S., \& Bozeman, B. (2005). The impact of research collaboration on scientific productivity. Social Studies of Science, 35(5), 673-702.

Masiello, I. (2009). Learning to succeed in European joint projects: The role of the modern project manager - the flow-keeper. Journal of Interprofessional Care, 23(5), 498-507.

Ordóñez-Matamoros, H.G., \& Cozzens, S.E. (2010). International co-authorship and research team performance in Colombia. Review of Policy Research, 27(4), 415-431.

Suter, E, Lait J, MacDonald, L, Wener, P, Law, R, Khalili, H \& McCarthy, P. (2011). Strategic approach to building research capacity in interprofessional education and collaboration. Healthcare Quarterly, 14(2), 54-60

Wenger, E. (1998). Communities of Practice: Learning, meaning and identity. Cambridge MS: Cambridge University Press

World Health Organization (2010). Framework for Action on Interprofessional Education \& Collaborative Practice. Available from: http://www.who.int/hrh/nursing midwifery/en/ (accessed Oct 11, 2011) 
GRIN Vision: Research and values informed/based interprofessional collaboration for global health.

GRIN Mission: To advance global collaborative interprofessional research in IECPCP.

\section{GRIN Values:}

- Cultural sensitivity and inclusivity

- Respect for diversity

- Knowledge sharing

- Interprofessional collaboration

- Quality inquiry

- Supportive mentorship

- Theory-based research

Box 1: GRIN: agreed vision, mission and values 


\section{For more information contact:}

Ruby Grymonpre

IPE Coordinator, University of Manitoba

GE706 Health Sciences Centre

820 Sherbrook Street

Winnipeg, MB R3A 1R9

Phone: 204-787-7562

Email: grymonpr@ms.umanitoba.ca

Hossein Khalili

Professor, Faculty of Health Sciences and Human Services,

Fanshawe College,

Room D3018, 1001 Fanshawe College Blvd. PO Box 7005

London, ON N5Y 5R6

Tel: 519-452-4430 Ext 2027

Email: hkhalili@fanshawec.ca 